\title{
Prevalence, Patterns and Disability Due to Musculoskeletal Disorders among Cotton Textile Industry Workers in Tamil Nadu - A Cross Sectional Study
}

\author{
Vinod H Krishnamoorthy, Deivasigamani Kuberan, Vijayaprasad Gopichandran*
}

\section{Vinod H Krishnamoorthy, Deivasigamani Kuberan, Vijayaprasad Gopichandran*}

Department of Community Medicine, ESIC Medical College and PGIMSR, KK Nagar, Chennai, Tamil Nadu, INDIA.

\section{Correspondence \\ Dr. Vijayaprasad Gopichandran, \\ Assistant Professor, Department of Com- munity Medicine, ESIC Medical College \\ and PGIMSR, KK Nagar, Chennai-600078, \\ Tamil Nadu, INDIA. \\ Phone no: +919445226806 \\ Email: vijay.gopichandran@gmail.com \\ History \\ - Submission Date: 09-07-2019 \\ - Revised Date: 04-10-2019 \\ - Accepted Date: 31-10-2019}

DOI : 10.5530/ijmedph.2019.3.17

Article Available online

http://www.ijmedph.org/v9/i3

\section{Copyright}

(C) 2019 Phcog.Net. This is an openaccess article distributed under the terms of the Creative Commons Attribution 4.0 International license.

\begin{abstract}
Background: Cotton textile industry employees use their neck, shoulder and upper limbs extensively in their work. However, there is no adequate documentation of the type of musculoskeletal morbidity among these workers. Objectives: To study the prevalence, patterns and disability due to musculoskeletal disorders among cotton textile industry workers in Tamil Nadu. Methods: The study was conducted in a cotton textile factory in Coimbatore. The factory was selected randomly from a list of medium scale factories. Stratified random sampling among supervisors, labourers and housekeeping staff in the factory was performed. The Nordic Musculoskeletal Questionnaire (NMQ) was used to collect information on pain in different areas of the body. Exploratory factor analysis was performed to group the pain, its severity and disability into syndromes. Based on the factor scores, the participants were grouped into clusters of pain patterns using K means cluster analysis. Results: A total of 100 participants responded to the study. The main syndromic patterns of musculoskeletal morbidity included - Acute upper limb pain, Chronic and acute pain in knee, ankles and feet, Acute and Activity limiting pain of back, hip and thighs, Chronic and Activity limiting pain in the back and shoulders, Activity limiting upper limb pain. Based on these syndromes, the participants were classified into three main clusters - cluster 1 - Acute, activity limiting pain of upper limb, low back, hips and thigh (13\%), cluster 2 - Acute pain of knees, ankle and feet (12\%) and cluster 3 - Activity limiting pain of upper back, shoulder and upper limb (75\%). Conclusion: The cotton textile industry workers had predominantly upper limb, upper back and shoulder musculoskeletal morbidity and disability, which needs to be addressed by appropriate ergonomic measures in the factories.
\end{abstract}

Key words: Cotton textile industry, Occupational health, Musculoskeletal disorders, Pain, Work related musculoskeletal disorders.

\section{INTRODUCTION}

It is well known that work posture and specific use of limbs for various work-related activities can lead to musculoskeletal symptoms. Poor ergonomic design at the workplace has lead to severe musculoskeletal morbidity among employees. ${ }^{1}$ Some of these musculoskeletal efforts are inherent to the nature of the work, whereas other wasteful muscular efforts can be prevented by appropriate ergonomic design of the equipments and workplace. ${ }^{2}$ Appropriate ergonomic design of workplace can substantially reduce musculoskeletal morbidity as well as improve work efficiency and productivity. ${ }^{3}$

Several studies among workers in various occupational sectors in India have shown that highest burden is due to musculoskeletal morbidity. A study of musculoskeletal disorders among farmers in Kanpur showed a high burden of low back pain, knee pain and shoulder pain. The study indicated that the prolonged standing and squatting posture adopted by the potato farmers lead to low back and knee pain. ${ }^{4}$ A study among dentists showed that there was a high prevalence of pain in the neck, wrist and hands, due to the nature of work related to dental procedures. ${ }^{5}$ Among workers in a bank working for long hours on the computer, the musculoskeletal morbidity profile showed a predominance of low back, upper back, neck and wrist pain, related to long hours of being seated in one place and working with the hands on the computer. ${ }^{6}$ In West Bengal, the work related musculoskeletal morbidity of brick field workers showed that there was a high prevalence of low back pain and neck due to frequent bending, bending and twisting of the body and working above shoulder height. ${ }^{\text {? }}$ Coir industry workers in Kerala, who stand for long hours and use their hands for twisting and winding the coir suffered more from low back pain. ${ }^{8}$ Among school teachers in the eastern and north-eastern parts of India, neck pain was the most common due to prolonged writing on the board above the shoulder level. ${ }^{9}$ These and other studies have shown that the musculoskeletal morbidity is one of the commonest health problem among workers in the occupational 
setting. The type of musculoskeletal morbidity depends on the nature of work.

A study of health problems of female textile industry workers in Puducherry showed that musculoskeletal morbidity is the commonest health problem. ${ }^{10}$ In a study of musculoskeletal morbidity among textile workers in Ahmedabad, the prevalence was not very high, however the pattern of musculoskeletal pain was predominantly low back, lower limb followed by upper limb pain. ${ }^{11}$ Though there is some information on the prevalence of musculoskeletal morbidity among textile industry workers, the exact patterns of the work related musculoskeletal disorders and their severity is not well documented. Most studies of musculoskeletal morbidity report the prevalence of pain and problems in mobility in different regions of the body, but do not document the level of disability due to the musculoskeletal morbidity. Therefore, this study was conducted to study the prevalence of musculoskeletal morbidity profile, patterns and level of disability among workers in a cotton textile industry in Coimbatore, Tamil Nadu.

\section{METHODS}

\section{Study Setting}

The study was carried out in Coimbatore, Tamil Nadu, which is one of the major industrial hub and highest revenue yielding district of the state. Due to the presence of an extensive cotton textile industry, the city is also referred to as the Manchester of India. The city houses several textile mills, all of which are fed by the cotton fields in the surrounding areas. The main processes that take place in many of these textile industries include - ginning, the process of separating cotton from the seeds, spinning, the process of converting the cotton to yarn, weaving, the process of converting yarn to fabric and finally dying, the process of imparting colour to the fabric. Many of the industries employ labourers who are involved in all these works. Especially in the small and middle scale industries, large parts of these works involve workers using their hands, lifting weights, bending, standing and sitting in the same posture for prolonged periods of time.

The factory where this study was conducted employs roughly 500 people working on various processes in converting bales of cotton into yarn. The heavy bales of cotton are fed into the plucker machines which clean it. This is then automatically passed to the drawing, combing and simplex process where the cotton is drawn out into $5 \mathrm{~mm}$ thick strands. There is substantial automation of work, but large parts of facilitation of the machinery and operation of the machinery involve manual labour. Major proportion of manual labour is involved in the final processes of twisting the fibres into fine yarn. There are three shifts per day and each shift is for a duration of 8 hours. There is a weekly shift change. The lunch break is for a duration of $45 \mathrm{~min}$. All the departments are equipped with humidification system which maintains $65 \%$ relative humidity and the desired temperature is ranging from 25 to 30 degree is fixed depending on the departments. This system also recycles the surrounding air bout 40 cycles per hour for removing the micro dusts.

\section{Study Participants}

Since the exact prevalence of musculoskeletal disorders among workers in the cotton textile industry in Coimbatore has not been documented before, the prevalence of $72 \%$ from a previous study from Puducherry was used as reference. ${ }^{10}$ To estimate a prevalence of $72 \%$ with a $20 \%$ relative precision and $95 \%$ confidence level, the required sample size was 39. To account for multistage sampling method, a design effect of 2 was applied and sample size of 78 obtained. Further accounting for a nonresponse rate of about $20 \%$ a total sample size of 94 was obtained, which was rounded off to 100 . Multistage sampling method was adopted with primary sampling unit being the industry. A list of middle scale cotton spinning factories was generated and one factory was selected randomly. In this factory, the list of employees under the three categories of labourers, housekeeping staff and supervisors was obtained. From each category proportionate number of employees were selected from the list by simple random sampling method. All employees, both men and women working under these categories were eligible to participate in the study.

\section{Study Instruments}

The selected participants were interviewed with the help of a structured, pretested, validated questionnaire containing the following details socio-demographic characteristics, musculoskeletal pain and disability obtained from the Nordic Musculoskeletal Questionnaire (NMQ). ${ }^{12}$ The Nordic Musculoskeletal Questionnaire uses a body map to indicate 9 sites of the body namely neck, shoulder, upper back, elbow, low back, wrist/hands, hips/thighs, knees and ankles/feet. The respondents were asked to respond about any pain in these 9 sites over the past 12 months, over the past 7 days as well as any pain that prevented activity of that region. When validated against clinical assessment, the tool was found to have a sensitivity of $92 \%$ and specificity of $88 \% .^{13}$

\section{Data Collection}

The selected participants were interviewed in a private area ensuring confidentiality of the information. They were shown the body map and asked to indicate the areas with pain and were asked the questions related to the duration, severity of pain and difficulty in activity of the pain area. The data were recorded using Google Forms for Android in a handheld digital electronic device. The collected data were exported as Excel spreadsheet.

\section{Statistical Analysis}

The data were analysed using SPSS Statistical Software package version 21. Simple descriptive statistics were analysed to understand the prevalence of musculoskeletal morbidity. To group the regions, severity and disability due to the musculoskeletal pain, Exploratory Factor Analysis was used using extraction based on eigenvalues greater than 1, Varimax rotation and suppression of all factor loadings less than 0.4 . The factor scores were used to group the participants into clusters with unique musculoskeletal morbidity patterns using the $\mathrm{K}$ means cluster analysis. The predominant patterns of musculoskeletal morbidity were analysed based on this clustering.

\section{Ethical Considerations}

Informed consent was obtained from all participants before collection of data. Data was collected in a private chamber and confidentiality of the data was ensured. The study was approved by the Institutional Ethical Committee of the institution of origin of this study.

\section{RESULTS}

A total of 100 respondents were approached and all of them consented to participate in the study. About half of the sample were between 18 and 30 years of age, with about $7 \%$ above 50 years. There was an almost equal distribution of men and women. About $35 \%$ of the participants had college education and $27 \%$ had never attended school. Most respondents were laborers in the cotton factory (52\%) with a small proportion of housekeeping staff and supervisors. Most of the participants (75\%) had monthly income of less than Rs. 20,000. These characteristics of the study sample are shown in Table 1.

The prevalence of musculoskeletal morbidity based on responses to the Nordic Musculoskeletal Questionnaire are shown in Table 2. It is seen that shoulder, neck, hip/thigh and back pain are the most common 


\begin{tabular}{|c|c|c|c|}
\hline S.no & Characteristic & Categories & No $\{\%\}$ \\
\hline \multirow[t]{4}{*}{1} & Age & 18 to 30 & 49 \\
\hline & & 31 to 40 & 32 \\
\hline & & 41 to 50 & 12 \\
\hline & & $>50$ & 7 \\
\hline \multirow[t]{2}{*}{2} & Sex & Male & 51 \\
\hline & & Female & 49 \\
\hline \multirow[t]{6}{*}{3} & Education & Middle school & 8 \\
\hline & & High school & 11 \\
\hline & & Higher secondary & 19 \\
\hline & & UG and Diploma & 33 \\
\hline & & PG & 2 \\
\hline & & No schooling & 27 \\
\hline \multirow[t]{3}{*}{4} & Marital status & Single & 22 \\
\hline & & Married & 77 \\
\hline & & Widowed & 1 \\
\hline \multirow[t]{3}{*}{5} & Designation & Supervisor & 29 \\
\hline & & Laborer & 52 \\
\hline & & Housekeeping staff & 19 \\
\hline \multirow[t]{5}{*}{6} & Monthly income & 5000 to 10000 & 32 \\
\hline & & 10001 to 20000 & 43 \\
\hline & & 20001 to 30000 & 13 \\
\hline & & 30001 to 50000 & 9 \\
\hline & & $>50000$ & 3 \\
\hline
\end{tabular}

chronic pain over past 12 months. Hip/thigh, back and neck pain are the most common acute pain over past 7 days and shoulder, hip/thigh and neck pain are the most common disabling pains.

The patterns of musculoskeletal symptoms were grouped based on Exploratory Factor Analysis into 5 major patterns namely - Acute upper limb pain, Chronic and acute pain in knee, ankles and feet, Acute and Activity limiting pain of back, hip and thighs, Chronic and Activity limiting pain in the back and shoulders, Activity limiting upper limb pain. This pattern of syndromic grouping of pain along with the factor loadings is shown in Table 3.

\begin{tabular}{|c|c|c|c|c|}
\hline S.NO & Region of the body & $\begin{array}{c}\text { Pain at any } \\
\text { time over } \\
\text { past } 12 \\
\text { months }\end{array}$ & $\begin{array}{c}\text { Acute pain } \\
\text { in the past } \\
7 \text { days }\end{array}$ & $\begin{array}{l}\text { Restricted } \\
\text { activities } \\
\text { due to pain }\end{array}$ \\
\hline 1 & Neck & 18 & 8 & 15 \\
\hline 2 & Shoulder & 35 & 7 & 26 \\
\hline 3 & Wrist/Hand & 12 & 5 & 9 \\
\hline 4 & Elbows & 5 & 5 & 5 \\
\hline 5 & Hip/Thigh & 24 & 10 & 19 \\
\hline 6 & $\begin{array}{l}\text { Back (Upper and } \\
\text { Lower) }\end{array}$ & 18 & 8 & 4 \\
\hline 7 & Knee & 9 & 3 & 9 \\
\hline 8 & Ankles/Feet & 12 & 5 & 4 \\
\hline
\end{tabular}

Table 3: Combination of musculoskeletal symptoms among the employees.

\begin{tabular}{|c|c|c|c|c|c|}
\hline & $\begin{array}{l}\text { Acute Upper Limb } \\
\text { pains }\end{array}$ & $\begin{array}{l}\text { Chronic and Acute } \\
\text { pain in knees, } \\
\text { ankle and feet }\end{array}$ & $\begin{array}{l}\text { Acute and Activity } \\
\text { Limiting pain in } \\
\text { back, hip and thighs }\end{array}$ & $\begin{array}{l}\text { Chronic and Activity } \\
\text { limiting pain in the } \\
\text { back and shoulder }\end{array}$ & $\begin{array}{l}\text { Activity Limiting upper } \\
\text { limb pain }\end{array}$ \\
\hline Acute pain in wrist and hand & .857 & & & & \\
\hline Acute pain in elbows & .798 & & & & \\
\hline Acute pain in the neck & .766 & & & & \\
\hline Acute pain in the shoulder & .547 & & & & \\
\hline Acute pain over ankles and feet & & .683 & & & \\
\hline Any pain in ankle and feet & & .667 & & & \\
\hline Any pain in the knees & & .510 & & & \\
\hline Acute Hip and Thigh pain & & & .753 & & \\
\hline Any pain in the Hip and Thighs & & & .741 & & \\
\hline $\begin{array}{l}\text { Reduced activities of daily living due } \\
\text { to shoulder pain }\end{array}$ & & & & .786 & \\
\hline Any pain in the shoulder & & & & .772 & \\
\hline Any pain in the back & & & & .627 & \\
\hline $\begin{array}{l}\text { Reduced activities of daily living due } \\
\text { to shoulder pain }\end{array}$ & & & & & .631 \\
\hline $\begin{array}{l}\text { Reduced activities of daily living due } \\
\text { to wrist and hand pain }\end{array}$ & & & & & .576 \\
\hline Any pain in the elbows & & & & & .509 \\
\hline
\end{tabular}


Any aches in the neck, wrists, reduced activities of daily living due to pain in neck, back, knees, ankles were removed from the analysis due to weak factor loading $(<0.4)$

$\mathrm{K}$ means cluster analysis of the factor scores obtained for each participant to cluster them into 3 major groups revealed a clustering as follows -

Cluster 1 - Acute, activity limiting pain of upper limb, low back, hips and thigh (13\%)

Cluster 2 - Acute pain of knees, ankle and feet (12\%)

Cluster 3 - Activity limiting pain of upper back, shoulder and upper limb (75\%)

Majority belonged to the upper back, shoulder and upper limb pain cluster. The cluster centre scores and grouping are shown in Table 4.

\section{DISCUSSION}

This study, conducted to understand the musculoskeletal morbidity prevalence, profile and disability among cotton textile industry workers in Coimbatore revealed that when considered as individual pain sites as contained in the Nordic Musculoskeletal Questionnaire, the highest prevalence was about $35 \%$, whereas when syndromic patterns of pain were identified, it was seen that $75 \%$ of the sample clustered in the activity limiting upper back, shoulder and upper limb pain cluster. The study also identified major syndromes of musculoskeletal morbidity among cotton textile industry workers based on the site involved, the duration of the pain and disability.

\section{Syndromic nature of musculoskeletal morbidity}

Work Related Musculoskeletal Disorders (WMSD) are a group of painful conditions involving muscles, bones, ligaments, tendons and joints. Some examples of work related musculoskeletal disorders include carpel tunnel syndrome, tennis elbow, tension neck syndrome etc. Majority of these WMSDs are localized to specific regions of the body which are used most during work. For example, prolonged sitting and bad posture during working on a computer may lead to tension neck syndrome. However, there are some jobs which demand use of specific groups of muscles which may not be localized. These workers develop WMSDs which involved more than one region. Identification of patterns in these WMSDs help in designing interventions to prevent severe work-related disability. Such patterns of WMSDs have been identified in previous studies. ${ }^{14,15}$ Most previous studies have captured the WMSD as unique areas of pain and as various degrees of pain. To the best knowledge of the authors, this study is the first which has looked at syndromic patterns of musculoskeletal morbidity not only with respect to pain, but with respect to pain, severity, duration and disability.

\section{Upper limb musculoskeletal morbidity pattern among cotton textile industry workers}

The textile industry, especially the spinning process in medium and small-scale industries involves a lot of work with the hands with the worker bent over for prolonged duration of time. It involves lifting bundles of cotton, separating them from the bigger bundle and setting them up for spinning. Therefore, there is extensive use of the hands for the work and difficult posturing in bent position straining the neck and upper back. Pain in these areas are the expected musculoskeletal morbidity patterns. As expected, the study revealed that activity limiting pain of the upper back, shoulder and upper limb was the most common pattern of musculoskeletal morbidity. Acute and activity limiting pain of the lower limbs and lower back were less common in this work group. This indicates a need for better ergonomic planning of the work place of the cotton textile industry.

\begin{tabular}{|c|c|c|c|}
\hline & 1 & 2 & 3 \\
\hline Acute Upper Limb pains & 1.38338 & -.16491 & -.21340 \\
\hline $\begin{array}{l}\text { Any and Acute pain in knees, } \\
\text { ankle and feet }\end{array}$ & -.27817 & 2.25487 & -.31256 \\
\hline $\begin{array}{l}\text { Acute and Activity Limiting pain } \\
\text { in lower back, hip and thighs }\end{array}$ & 1.45716 & .19588 & -.28392 \\
\hline $\begin{array}{l}\text { Any and Activity limiting pain in } \\
\text { the upper back and shoulder }\end{array}$ & -.26330 & -.06279 & .05569 \\
\hline $\begin{array}{l}\text { Activity Limiting upper limb } \\
\text { pain }\end{array}$ & .01579 & -.25031 & .03731 \\
\hline
\end{tabular}

\section{Measuring musculoskeletal disability in addition to morbidity}

Most previous studies of musculoskeletal morbidity in occupational settings have reported the patterns and severity of pain., ${ }^{24-6}$ There have been very few reports of disability caused by the WMSDs. This study reports the disability in terms of self-report of limitations of use of the area of pain. In this study it is seen that the upper limb musculoskeletal morbidity is not just severe in nature, but it is also disabling in that it limits activities of the upper limb. Such disability is a cause for concern as it is likely to increase absenteeism at work place and reduce productivity. Therefore, it is important to include disability as an indicator of WMSDs in all assessments of this condition.

\section{Strengths and limitations of this study}

The strengths of this study include the fact that it is to the best of the author's knowledge the first study to explore the syndromic patterns of musculoskeletal morbidity among workers in a cotton textile industry. The systematic use of the Nordic Musculoskeletal Questionnaire and application of robust statistical methods to identify musculoskeletal pain clusters is a strength of this study. There are a few limitations which need to be borne in mind. The small sample size of 100 , though statistically justified, is likely to under-represent the burden of the problem. Moreover, the participants belonged to a single factory, which again may limit the generalizability of the findings. There is also a possibility of reporting bias as the Nordic Musculoskeletal Questionnaire captured the subjective experience of pain and there was no method to objectively validate this. Despite these limitations, the methodology of syndrome identification and identification of musculoskeletal pain clusters is unique and can be followed in future studies.

\section{CONCLUSION}

This study identified that workers in a cotton textile industry have a unique pattern of musculoskeletal morbidity involving activity limiting pain of the upper back, shoulder and upper limb. This is probably related to the nature of work in the cotton industry. This finding should inform ergonomic interventions in cotton textile industries to improve the work conditions of the employees.

\section{ACKNOWLEDGEMENT}

The authors would like to acknowledge the support of the cotton textile manager, employees and housekeeping staff who participated in this study.

\section{CONFLICT OF INTEREST}

The authors declare no conflict of interest. 


\section{ABBREVIATIONS}

NMQ: Nordic Musculoskeletal Questionnaire; SPSS: Statistical Package for Social; UG: Undergraduate; PG: Postgraduate; WMSD: Work Related Musculoskeletal Disorders.

\section{REFERENCES}

1. Ijadunola KT, ljadunola MY, Onayade AA, Abiona TC. Perceptions of occupationa hazards amongst office workers at the Obafemi Awolowo University, Ile-Ife. Niger. J Med J Natl Assoc Resid Dr Niger. 2003;12(3):134-9.

2. Thompson SK, Mason E, Dukes S. Ergonomics and cytotechnologists: Reported musculoskeletal discomfort. Diagn Cytopathol Wiley Online Library. 2003;29(6):364-7.

3. Huang GD, Feuerstein M. Identifying work organization targets for a work-related musculoskeletal symptom prevention program. J Occup Rehabil Springer. 2004;14(1):13-30

4. Gupta G, Tarique T. Prevalence of Musculoskeletal Disorders in Farmers of Kanpur-Rural, India. J Community Med Heal Educ. 2013;3(249):2161-0711. Available from: https://www.omicsonline.org/prevalence-of-musculoskeletal-disordersin-farmers-of-kanpurrural-india-2161-0711.1000249.php?aid=17960\%0D

5. Kumar V, Kumar S, Baliga M. Prevalence of work-related musculoskeletal complaints among dentists in India: A national cross-sectional survey. Indian J Dent Res. 2013;24(4):428-38. Available from: http://www.ijdr.in/article. asp?issn $=0970-9290$

6. Moom RK, Sing LP, Moom N. Prevalence of Musculoskeletal Disorder among Computer Bank Office Employees in Punjab (India): A Case Study. Procedia Manuf. 2015;3:6624-31. Available from: http://www.sciencedirect.com/science/
article/pii/S235197891501118X

7. Das B. Prevalence of Work-related Musculoskeletal Disorders Among the Brick Field Workers of West Bengal, India. Arch Environ Occup Health Routledge. 2014;69(4):231-40. Available from: https://doi.org/10.1080/19338244.2013.771 249

8. Satheeshkumar M, Krishnakumar K. Study on Work-Related Musculoskeletal Disorders among Coir Industry Workers in the State of Kerala, India. Ergon Des Prod Work: $21^{\text {st }}$ Century Perspect. Asia. $1^{\text {st }}$ ed. Singapore: Springer. 2018.

9. Damayanti S, Zorem M, Pankaj B. Occurrence of Work Related Musculoskeletal Disorders among School Teachers in Eastern and Northeastern Part of India. Int J Musculoskelet Pain Prev. 2017;2(1):187-92.

10. Subitha L, Roy G. Pattern of morbidity among female textile workers in Puducherry, South India. Int J Med Public Heal. 2016;6(3):140-3.

11. Chauhan SK, Chauhan A, Shukla A. A Cross-Sectional Study on Musculoskeletal Disorders among Textile Mill Workers in Ahmedabad City. J Med Sci Clin Res. 2016;4(10):13210-3

12. Crawford JO. The Nordic musculoskeletal questionnaire. Occup Med: Oxford University Press. 2007:57(4):300-1.

13. Dickinson CE, Campion K, Foster AF, Newman SJ, O'Rourke AM, Thomas PG. Questionnaire development: An examination of the Nordic Musculoskeletal questionnaire. Appl Ergon England. 1992;23(3):197-201.

14. Henry LJ, Jafarzadeh EA Ramli A, Ishak I, Justine M, Mohan V. Patterns of work-related musculoskeletal disorders among workers in palm plantation occupation. Asia Pacific J Public Heal China. 2015;27(2):NP1785-92.

15. Ojukwu CP, Anyanwu GE, Eze B, Chukwu SC, Onuchukwu CL, Anekwu EM. Prevalence, Pattern and Correlates of Work-related Musculoskeletal Disorders among School Teachers in Enugu, Nigeria. Int J Occup Saf Ergon: Taylor and Francis. 2018;1-31. Available from: https://doi.org/10.1080/10803548.2018.1495 899

Cite this article : Krishnamoorthy VH, Kuberan D, Gopichandran V. Prevalence, Patterns and Disability Due to Musculoskeletal Disorders among Cotton Textile Industry Workers in Tamil Nadu - A Cross Sectional Study. Int J Med Public Health. 2019;9(3):66-70. 